\title{
A declining pattern of malaria prevalence in Asendabo Health Center Jimma zone, Southwest Ethiopia
}

\author{
Abdurazak Jemal and Tsige Ketema*
}

\begin{abstract}
Objective: To assess the status of malaria prevalence in one of the malaria endemic areas of Ethiopia.

Results: A 10-year report of malaria cases were obtained from Asendabo Health Center, Jimma zone, Southwest Ethiopia. Following a retrospective study design, data of 68,421 febrile patients diagnosed and treated in the health center were included in the study. The year with the highest prevalence rate (34.9\%) was 2010, whereas the lowest was $2016(0.62 \%)$. The number of diagnosed malaria cases from September to November were significantly higher $(\mathrm{P}=0.023, \mathrm{n}=6336,46.5 \%)$ than in other months. Plasmodium falciparum $(52.1 \%, \mathrm{n}=7087)$ and Plasmodium vivax $(44.2 \%, n=6009)$ were the two principal plasmodium species accountable for malaria infections in the study area. The current study is a supportive evidence for the reduction of malaria prevalence in malaria endemic areas of Ethiopia.
\end{abstract}

Keywords: Malaria, Prevalence, P. falciparum, P. vivax, Seasonal variation

\section{Introduction}

Malaria is one of the top public health concerns of the nations in tropical and sub-tropical regions of the world. It is a major cause of morbidity and mortality in Africa [1]. Reports in 2005, showed that global estimate of deaths that occurred annually from malaria was 1-3 million [2]. However, a recent report of World Health Organization (WHO) showed a significant reduction of malaria associated deaths to 584,000 globally in 2013 [3]. Other reports by WHO has also indicated the reduction of malaria-related deaths among African children since 2000 [4].

In Ethiopia malaria is still one of the major health problems in some parts of the country. According to the Federal Ministry of Health (FMoH) report, about $60 \%$ of the country's populations live in malaria endemic areas [5]. To create malaria-free nation, government has set a big goal of eliminating malaria by 2020 [5]. To achieve the set goal, all concerned bodies in the country have shown a strong commitment. Hence, the country has been able

\footnotetext{
*Correspondence: tsigeketema@gmail.com

Department of Biology, College of Natural Sciences, Jimma University,
} Jimma, Ethiopia to achieved about $50 \%$ overall malaria reduction goal by 2015 [6]. This remarkable achievement was attained mainly due to the implementation of intensive interventional strategies such as indoor residual spraying, use of bed nets, and combination chemotherapy [7]. However, in some endemic areas of the same country, this reduction has not yet been achieved and even it is a major cause of illness and death [8]. One of the regions that have so far achieved remarkable malaria burden reduction is Oromia [9]. Jimma zone is one of malaria-endemic areas in the region and Asendabo is one of malaria endemic districts found in the zone (https://en.wikipedia. org/wiki/Jimma_Zone). In the district, intensive malaria interventional approaches have been executed for a long time. Thus, the current study was designed to assess the status of malaria prevalence in this district and draw the experience that could be shared by other similar districts.

\section{Main text \\ Methods \\ Study area}

The study was conducted in Asendabo district, located at $303 \mathrm{~km}$ southwest of Ethiopia. This district is one of the malaria endemic areas in the zone and received special 
attention from national and regional governments, NGOs and public institutions such as Jimma University, Center for tropical and infectious disease on malaria prevention and control campaigns [personal communication]. The district has only one health center that serves about a population of 33,981 (unpublished data from zonal health office). Malaria is one of the major health problems of the district. The two main plasmodium species: $P$. vivax and P. falciparum are responsible for malaria infection and Anopheles arabiensis is known as principal vector transmitting malaria in the district.

\section{Study design and data collection process}

A retrospective study was conducted to determine the prevalence of malaria by reviewing febrile patients' medical record at Asendabo Health Center from September 2007 to August, 2017 (10 year period). Patients were diagnosed and treated following a standard operating procedure for malaria diagnosis. Peripheral blood smear examination was used to confirm malaria infection as per the recommendation of WHO. All the variables recoded and documented for each patients such as Age in range, sex, blood film status (+ve and -ve), plasmodium species (P. falciparum, $P$. vivax and mixed infection), and data of diagnosis on the weekly malaria reporting format were considered in the study.

\section{Data analysis}

Data was checked for correctness, and analyzed using SPSS (Armonk, NY: IBM Corp) version 20.0 software. Descriptive statistical tests were used for analysis of malaria prevalence, seasonal variation and demographic data. A One sample T-test and Relative Risk test were statistical tools used to analyze differences between means of variables and to show relative risk of different groups to malaria respectively. Significance level was considered at confidence interval (CI) of $95 \%$.

\section{Results}

\section{Trends of malaria prevalence}

In the current study data of 68,421 febrile patients diagnosed and treated in the health center over the 10 years were considered. About 13, 624 of them were malaria positive. This showed an aggregate malaria prevalence of $20.7 \%$ (95\% CI 20.37-20.99) among febrile patients. From the positive patients, $52.5 \%(\mathrm{n}=7138,95 \%$ CI 51.32 $53.65)$ were males and $47.5 \%(n=6457,95 \%$ CI 46.28 to 48.73 ) were females. Prevalence of malaria among biologically risked group, children $<5$ years, was $24.4 \%$ $(\mathrm{n}=3315,95 \%$ CI 22.91-25.86) (Table 1). Although the proportion of malaria positive children was large, their relative risk to acquire the infection compared to the adult's $(\mathrm{RR}=0.77,95 \%$ CI $0.75-0.803)$ was significantly low.

Although the cumulative 10 years prevalence of malaria in febrile patients shown high, the trend in the study area has a declining pattern, from $27.9 \%$ in 2007 to $0.62 \%$ in 2016 . The highest malaria prevalence among febrile patients $(34.9 \%, \mathrm{n}=4963)$ was documented in the year 2010 and followed by $2009(29.4 \%, \mathrm{n}=2104)$. The recent year's assessment showed that, starting from 2013 to 2016, the prevalence was drastically reduced from two digits to $0.6 \%$ (1.375 averages) (Table 1$)$. In 2016/2017, from September, 2016 to August, 2017, a total of 2619 febrile cases were examined for malaria infection. Only 29 (1.1\%) of them were malaria positive. This showed that the declining pattern was persistent with slight increment from $0.6 \%(18 / 2874)$ in $2015 / 16$

Table 1 Trend showing 10 years malaria prevalence in Asendabo Health Center (2007-2016)

\begin{tabular}{|c|c|c|c|c|c|c|}
\hline \multirow[t]{2}{*}{ Year } & \multirow[t]{2}{*}{ Total examined } & \multirow[t]{2}{*}{ Malaria positive } & \multirow[t]{2}{*}{ Malaria prevalence } & \multicolumn{2}{|c|}{ Patients in sex } & \multirow[t]{2}{*}{$<5$ years $(\%)$} \\
\hline & & & & Male (\%) & Female (\%) & \\
\hline 2007 & 6497 & 1814 & 27.9 & $953(52.5)$ & $861(47.5)$ & $392(21.6)$ \\
\hline 2008 & 6506 & 1802 & 27.7 & $910(50.5)$ & $892(49.5)$ & $375(20.8)$ \\
\hline 2009 & 7266 & 2104 & 28.9 & 1058 (50.3) & 1046 (49.7) & $617(29.3)$ \\
\hline 2010 & 14,235 & 4963 & 34.9 & $2670(53.8)$ & $2293(46.2)$ & 1205 (24.3) \\
\hline 2011 & 9095 & 1916 & 21.1 & $1020(53.2)$ & $896(46.8)$ & $452(23.6)$ \\
\hline 2012 & 7218 & 770 & 10.7 & $401(52.1)$ & $369(47.9)$ & $211(27.4)$ \\
\hline 2013 & 4578 & 137 & 2.99 & $76(55.5)$ & $61(44.5)$ & $35(25.5)$ \\
\hline 2014 & 3654 & 38 & 1.04 & $21(55.3)$ & $17(44.7)$ & $6(15.8)$ \\
\hline 2015 & 3879 & 33 & 0.85 & $15(45.5)$ & $18(54.5)$ & $13(39.4)$ \\
\hline 2016 & 2874 & 18 & 0.62 & $14(77.7)$ & $4(22.2)$ & $9(50)$ \\
\hline 2017 & 2619 & 29 & 1.1 & $18(62.1)$ & $11(37.9)$ & $10(34.5)$ \\
\hline Total & 65,802 & 13,595 & 20.7 & 7138 (52.5) & 6457 (47.5) & 3315 (24.4) \\
\hline
\end{tabular}


to $1.1 \%(29 / 2619)$ in $2016 / 2017$, but not significantly different $(\mathrm{P}=0.056)$. Majority of the positive cases $(\mathrm{n}=17,58.6 \%)$ were registered in a month (August). Among the total 29 positive patients observed, $n=10$ were children $<5$ years. The two Plasmodium species were accountable for malaria infections in the study area. About 52.1\% $(\mathrm{n}=7087)$ and $44.2 \%(\mathrm{n}=6508)$ malaria cases were infected with Plasmodium falciparum and $P$. vivax respectively. The remaining $7.7 \%$ were due to mixed ( $P$. falciparum and $P$. vivax) infection (Fig. 1).

\section{Seasonal variation and prevalence of malaria}

From the analysis made to assess role of seasonal variations on the prevalence of malaria among febrile patients, it was observed that Autumn season (from September to November in Ethiopia) was found as malaria peak season in the study area. In other seasons such as Spring, Winter and Summer, the prevalence pattern seems similar. Number of malaria diagnosed patients in Autumn $(46.5 \%, \mathrm{n}=6336)$ was significantly higher $(\mathrm{P}=0.023)$ than other seasons. Seasonal variation showed effects on the type of plasmodium parasite infection. While P. falciparum and $P$. vivax were the two dominant parasite, prevalence of $P$. vivax among febrile patients was significantly higher $(P=0.042)$ compared to P. falciparum during Winter season (December to

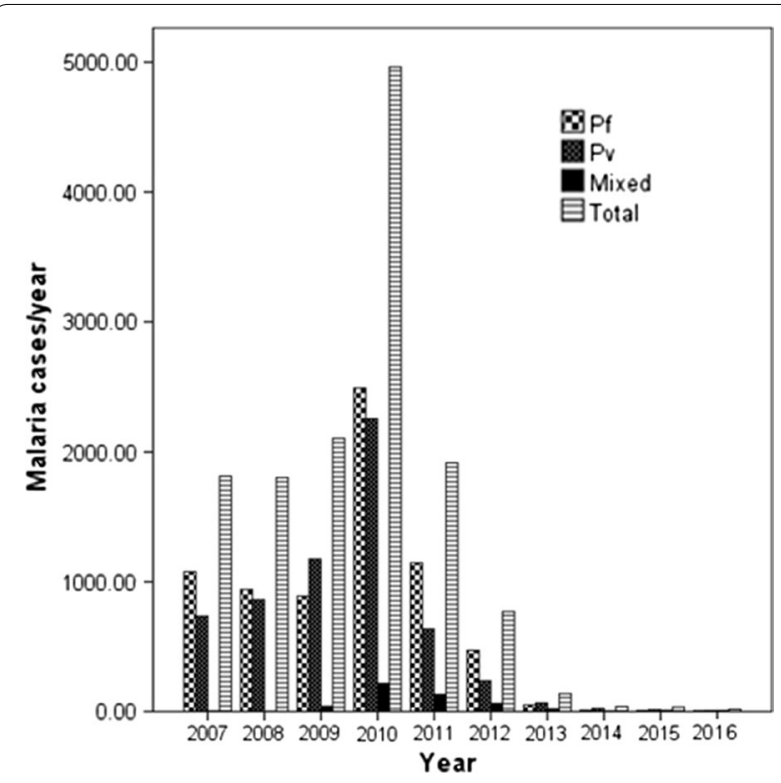

Fig. 1 Plasmodium species accountable for malaria infection in Asendabo Health Center (2007-2016). Pf: Plasmodium falciparum; Pv: Plasmodium vivax; Mixed: infection with both P.f and P.V
February in Ethiopia) than other seasons (Additional file 1).

\section{Discussion}

In the current study the aggregate 10 years malaria prevalence observed was $20.7 \%$. The prevalence rate was varies from $34.9 \%$ prevalence in 2010 to $0.62 \%$ in 2016. Similar to the situation in other developing countries, malaria was the major public health problem in the study area. However, recently due to a strong commitment shown by concerned bodies, the prevalence of malaria is radically reducing in most parts of the country [6]. Thus, the observed significant reduction in malaria prevalence may suggest the effectiveness of the interventional strategies adopted in the study area.

While the decreasing pattern of malaria prevalence throughout the 10 year was consistent, the fact that slight increment observed in the recent year (2016/17) has indication of possibility of malaria resurgence in the study area. Although it is possible to achieve remarkable malaria prevalence reduction, complete elimination of the infection is impossible $[10,11]$. This could be due to the presence of persistent residual infection transmission and the biological nature of the parasite [12]. Thus, close monitoring and surveillance of the interventional strategies and the infection pattern is very important in such locality.

One of the determinant factors for malaria transmission is seasonal variation. Temperature and humidity are variables that govern plasmodium parasite growth in the vector body, and the vector development in the environment. Thus, optimum environmental condition is very important for the disease to transmit. Autumn season (after heavy rain) was found to be a malaria peak transmission season in the study area [13]. This finding is in agreement with a report of Jamil and Khan [14] from Pakistani and Woyessa et al. [15] from Butajira-Ethiopia, where prevalence of $P$. falciparum malaria reached its highest frequency after heavy rain.

One of the factors that might have contributed to the successful malaria reduction in the country is, direct involvement of health extension workers (HEWs) in malaria control and prevention campaign [16]. Their major role is enhancing awareness of the community towards malaria infection, its transmission, and on how to use of different prevention methods in malaria endemic areas $[16,17]$. These workers spend $75 \%$ of their time visiting families in their homes and performing outreach activities in the community and distribute artemisinin-based combination therapy (ACT) to the needy community [18]. Thus, presence of HEWs is one of the important factors for early observation and reporting of malaria cases, for further diagnosis at the nearby 
health facilities, and to get treatment with appropriate antimalarial drugs [19]. This could be considered as best practice to be shared by other similar people living in malaria endemic areas in the country and beyond, with similar set-up. In general the use of bed net, IRS, combination therapy and contribution of different stakeholders including HEW might have a great role for the declining of malaria infection in the study area [20].

\section{Conclusion}

The current study provides supportive evidence for the reduction of malaria prevalence in Jimma zone, Asendabo district. This could serve as a sign for the rise in commitment of all stakeholders to eliminate malaria from the country. The observed declining of malaria prevalence among febrile patients in this study is a promising outcome which could be cascaded to other malaria endemic areas.

\section{Limitation}

This study was delimited to only one district. More concrete evidences could have been generated had it been included more malaria-endemic areas in the zone. In addition, only those patients seeking medication and visited the health center during the study period were included in the study. Data of other suspected malaria patients treated at home or used other traditional medication was not included in the study.

\section{Additional file}

Additional file 1: Figure S1. Prevalence of plasmodium species with respect to seasonal variation at Asendabo Health Center, (January, 2007August, 2016).

\section{Abbreviations}

ACT: artemisinin combination therapy; DDT: dichlorodiphenyltrichloroethane; FDRE: Federal Democratic Republic of Ethiopia; HEW: health extension workers; IRS: indoor residual spraying; LLITN: long-lasting insecticide treated nets; UNICEF: United Nations Children's Fund; WHO: World Health Organization.

\section{Acknowledgements}

The authors would like to thank officials of Asendabo Health Center for provision of the data and the study participants for their willingness to participate in the study and genuine response.

\section{Authors' contributions}

TK and AJ were involved in the designing of this study, data collection, analysis and write-up. TK also involved in the supervision of the research. All authors read and approved the final manuscript.

\section{Funding}

This work was financially supported by Jimma University. This funding body had no role in the design, collection, data analysis, interpretation and reporting of data or in writing the manuscript.

\section{Availability of data and materials}

The datasets supporting the conclusions of this article are included within the manuscript.

\section{Ethics approval and consent to participate}

The study was ethically approved by Research and Ethical Review Board of College of Natural Sciences, Jimma University. All data were generated based on the official permission obtained from concerned offices. Written or verbal consent from participants was not applicable.

\section{Consent to publish}

Not applicable.

\section{Competing interests}

The authors declare that they have no competing interests.

Received: 3 December 2018 Accepted: 22 May 2019

Published online: 27 May 2019

\section{References}

1. WHO. Malaria control today, 2005. 2005. http://www.who.int/malaria/ docs/malaria_control_today_2005.pdf. Accessed 15 Apr 2017.

2. Snow RW, Guerra CA, Noor AM, Myint HY, Hay SI. The global distribution of clinical episodes of Plasmodium falciparum malaria. Nature. 2005;434(7030):214-7.

3. WHO. World malaria report. Geneva: World Health Organization; 2015

4. WHO. World malaria report 2014. Geneva: World Health Organization; 2014. http://www.who.int/malaria/publications/world_malaria_repor t 2014/report/en. Accessed 3 Sept 2018.

5. FMoH. National malaria program monitoring and evaluation plan 2014 2020. Addis Ababa: Federal Democratic Republic of Ethiopia Ministry of Health; 2014.

6. Deribew A, Dejene T, Kebede B, Assefa G, Adama Y, Misganaw A, et al. Incidence, prevalence and mortality rates of malaria in Ethiopia from 1990 to 2015: analysis of the global burden of diseases 2015. Malar J. 2017;16(1):271.

7. Jima D, Medhin A. Malaria prevention and control in Ethiopia: progress and prospects. Fed Democr Repub Ethiop Minist Health Q Health Bull. 2008;1:10-8.

8. Geleta G, Ketema T. Severe malaria associated with Plasmodium falciparum and P. vivax among children in Pawe Hospital, Northwest Ethiopia. Malaria Res Treat. 2016;56:67. https://doi.org/10.1155/2016/1240962.

9. Olana D, Chibsa S, Teshome D, Mekasha A, Graves PM, Reithinger R. Malaria, Oromia regional state, Ethiopia, 2001-2006. Emerg Infect Dis. 2011;17(7):1336-7. https://doi.org/10.3201/eid1707.100942.

10. Killeen GF. Characterizing, controlling and eliminating residual malaria transmission. Malar J. 2014;13:330.

11. Smith DL, Cohen JM, Chiyaka C, Johnston G, Gething PW, Gosling R Buckee CO, Laxminarayan R, Hay SI, Tatem AJ. A sticky situation: the unexpected stability of malaria elimination. Philos Trans R Soc Lond B Biol Sci. 2013;368:20120145.

12. Killeen GF, Seyoum A, Sikaala CH, Zomboko AS, Gimnig JE, Govella NJ, White MT. Eliminating malaria vectors. Parasites Vectors. 2013;6:172.

13. Wiwanitkit $V$, Suyaphun $A$. Seasonal variation in the prevalence of Plasmodium vivax malarial infection: an observation in northern Thailand. Medscape Gen Med. 2005;7(2):7.

14. Jamil S, Khan MN. Seasonal variations of vivax and falciparum malaria: an observation at a tertiary care hospital. J Ayub Med Coll Abbottabad. 2012;24(1):93-5.

15. Woyessa A, Deressa W, Ali A, Lindtjorn B. Prevalence of malaria infection in Butajira area, south-central Ethiopia. Malar J. 2012;11:84.

16. Teklehaimanot $\mathrm{H}$, Teklehaimanot $\mathrm{A}$. Human resource development for a community-based health extension program: a case study from Ethiopia. Hum Resour Health. 2013;11:39.

17. Medhanyie A, Spigt M, Kifle Y, Schaay N, Sanders D, Blanco R, GeertJan D, Berhane $Y$. The role of health extension workers in improving utilization of maternal health services in rural areas in Ethiopia: a cross sectional study. BMC Health Serv Res. 2012;12:352. 
18. Sebhatu A. The implementation of Ethiopia's Health Extension Program, Ethiopia Good Practice: HEP; 2008. p. 2-5.

19. Birhanu Z, Abebe L, Sudhakar M, Dissanayake G, Yihdego YY-E, Alemayehu $G$, et al. Malaria related perceptions, care seeking after onset of fever and anti-malarial drug use in malaria endemic settings of southwest Ethiopia. PLoS ONE. 2016;11(8):e0160234.

20. Gemechu T, Samuel A, Yewhalaw D. Ten years trend analysis of malaria prevalence in relation to climatic variables in Sibu Sire District, East
Wollega Zone, Oromia regional State, Western Ethiopia: a retrospective study. Sci Technol Arts Res J. 2015;4(4):99-105.

\section{Publisher's Note}

Springer Nature remains neutral with regard to jurisdictional claims in published maps and institutional affiliations.
Ready to submit your research? Choose BMC and benefit from:

- fast, convenient online submission

- thorough peer review by experienced researchers in your field

- rapid publication on acceptance

- support for research data, including large and complex data types

- gold Open Access which fosters wider collaboration and increased citations

- maximum visibility for your research: over $100 \mathrm{M}$ website views per year

At BMC, research is always in progress.

Learn more biomedcentral.com/submissions 